\title{
The Open Algorithm Based on Numbers (ABN) as an Educational Innovation for Teaching and Learning in Ecuador
}

\author{
Derling Jose Mendoza Velazco ${ }^{1 *}$, Magda Francisca Cejas Martinez ${ }^{2,3}$, Carlos Alban Yanez ${ }^{2}$, \\ Yanet Marisol Ortega ${ }^{2}$
}

\author{
${ }^{1}$ Universidad Nacional de Educación, ECUADOR \\ 2 Universidad de las Fuerzas Armadas, ESPE, ECUADOR \\ ${ }^{3}$ Universidad Nacional de Chimborazo, UNACH, ECUADOR \\ *CORRESPONDENCE: $\square$ derling969@gmail.com
}

\begin{abstract}
To prevent difficulties in learning mathematics, effective and innovative teaching methodologies should be used. The present study presents the results of a relational and comparative study between the application of the open number-based algorithm $(A B N)$ and the closed numberbased algorithm (CNB) method. The research was of a descriptive cross-sectional quantitative type. Descriptive and comparative, quasi-experimental cross-sectional design study. The sample was 320 students of the first cycle of the National University of Education (UNAE). A multiple choice questionnaire with geometry exercises and a Likert type scale was applied for the data collection. The results were analyzed through an analysis of variance (ANOVA). We worked with two variables, the informal geometric reasoning variable and the formal geometric reasoning variable. We applied a correction of the degrees of freedom with Welch's robust test. The results indicated that the ABN-oriented group $(n=151)$ achieved better results than the CNB-oriented group $(n=92)$. The results were relevant, because the skills demonstrated in the results, show that the $A B N$ method reinforces the capacity to give solution to the exercises, contributing to the development of the numerical sense. Concluding that it can be described as a flexible or innovative model in the field of mathematics teaching.
\end{abstract}

Keywords: mathematical education, ABN methodology, geometry, educational innovation

\section{INTRODUCTION}

Mathematics is a key component for the intellectual development of the human being and of society. On many occasions, students at the university level do not consider it this way, and visualize the teaching of mathematics in a different way (Weiland et al. 2019). In fact, it can be said that mathematics is an area of knowledge that people know well, that even citizens who have never attended school are capable of developing calculation tools necessary for their daily lives. It is understood that mathematics is a universal language that makes it the main tool to abstract, generalize and synthesize all information. Thanks to mathematics, people can develop their logic and critical thinking, which allows us to solve increasingly difficult problems (Amanat \& Reid, 2012; Zambak \& Tyminski, 2020).

In Ecuador, mathematics is an important pillar in society, being fundamental for the economic growth of the country. The growing concern of the Ministry of Education of Ecuador (2016) contributes to support resources for research. The design of didactic guides and distribution of complementary material, allows the improvement of the educational system (Alquinga, 2018). Various teaching methods have been proposed to

Article History: Received 12 May $2020 \bullet$ Revised 20 June $2020 \bullet$ Accepted 4 July 2020

(C) 2020 by the authors; licensee Modestum. Open Access terms of the Creative Commons Attribution 4.0 International License (http://creativecommons.org/licenses/by/4.0/) apply. The license permits unrestricted use, distribution, and reproduction in any medium, on the condition that users give exact credit to the original author(s) and the source, provide a link to the Creative Commons license, and indicate if they made any changes. 


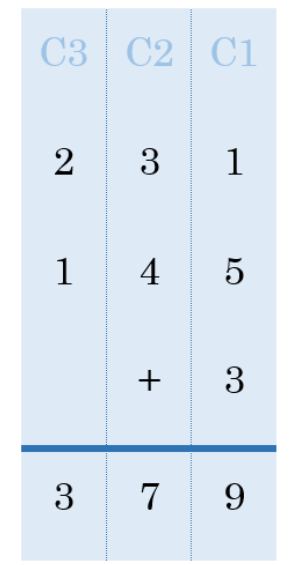

Figure 1. Traditional summation method

overcome learning difficulties in mathematics (Pari, 2017). The updating of teachers has been requested, making use of new technologies such as GeoGebra, Wiris among others according to Barahona et al. (2015). Authors such as Navarro and Navarro (2015) recommend the use of techniques with proven effectiveness in this area, such as the Copy, Cover and Compare method or Direct Instruction with Flash Cards.

Bracho and Adamuz (2014) have considered and insisted on the importance of considering to individual differences in teaching, based on the particularities and the learning rhythms of each student. Therefore, it is necessary to focus efforts not only on proposing specific and remedial interventions in the face of learning difficulties. It is also necessary to analyse whether the teaching methods applied in classrooms are appropriate for the students and take into account their diversity. Teachers spend a lot of effort, resources, courses and time teaching basic operations. In these cases, students are limited to memorizing instructions and working with figures (Aragón, Delgado, \& Marchena 2017b).

Consequently, students are not taught in a meaningful way. Nor are they prepared to deduce, reflect or extrapolate ideas and concepts. They are not trained in mental calculation or estimation. Furthermore, this type of teaching is often applied in a decontextualised manner. In mathematics classes, students are limited to solving accounts automatically. Students do not propose operations in a real context; they do not give meaning to the learning situation (Díaz, Torres, \& Lozano 2017). Given this problem, the study is based on two methodological components of mathematics teaching. The algorithm based on numbers (ABN) and the traditional closed method based on numbers (CNB), which are described below.

\section{Traditional Closed Method Based on Numbers CNB}

The CNB method is highlighted as the traditional method of teaching mathematics. First, Ecuadorian students spend a lot of time learning the traditional algorithms of the four basic operations (addition, subtraction, multiplication and division). Then, at the high school level, repetitive lessons in geometry are applied. Students are constantly formulating to do various complex mathematical operations (Rodríguez, Celorio, \& Gutiérrez 2019).

Students must learn one set of data. They must memorize tables and a limited set of instructions, thus combining numbers in a predetermined and procedural way (Mendoza \& Mendoza 2018). Therefore, they are only required to have a very good memory. They are never instructed to calculate by breaking down the numbers, nor do they instruct them to use mental calculation and estimation. In this case, students do not have to think, reflect, deduct or extrapolate knowledge, they operate only with numbers and not with logic (Martínez, 2011).

Secondly, the CNB contemplates operations that are insufficient. The traditional method requires a way of calculating without flexibility and without control of the intermediate steps in the calculations. In that case, students do not have a complete idea of the meaning of numbers. It is essential to guide students who can put numbers in different ways, either horizontally or vertically. But the CNB is required to be vertical. Inappropriate number placement invalidates all results (Brasch, Williams, \& McLaughlin 2008). For example, adding the numbers $231+145+3$ is represented in Figure 1 . 
Table 1. Addition, applying the ABN number-based algorithm method

\begin{tabular}{ccccc}
\hline r1 & & $231+145+3$ & \\
\hline r2 & & 234 & & 145 \\
\hline r3 & Added & is left & 345 \\
\hline r3 & 200 & 34 & 375 \\
r4 & 30 & 4 & 379 \\
\hline r5 & & 4 & \\
\hline
\end{tabular}

The digits or quantities to be added must be arranged vertically. The summation starts from the left. The digits in the first column "C1" are added together $(1+5+3=9)$. Then the digits in "C2" are added together $(3+4$ $=7)$. Finally, in the third column "C3" the digits 2 and 3 are added, $(2+1=3)$. When adding from left to right, the values that exceed the whole of new, a unit is saved to the next amount. In addition, with the traditional methodology, students have to calculate by breaking the numbers, numeral by numeral. They cannot break the same order of units and cannot combine two different orders. Only the results obtained at the end of the application of the whole algorithm are considered. In addition, students have no control over the data they are calculating, because they are not set in a real context. This methodology is practiced every day in Ecuador to solve arithmetic operations. Teachers say that this problem is due to their low reading comprehension. It has already been shown in several studies that the reading comprehension level is not the main cause of poor performance in solving the problem, because when children develop oral problems they continue to have the same difficulties (Alquinga, 2018).

Finally, the traditional CNB methodology requires a similar level of difficulty. That is, all students have to perform the same operations and problems. In addition to these disadvantages, the teaching of basic operations through traditional algorithms does not allow the use of results or intermediate steps. All are governed by a standard or procedure. Giving the methodology a very inflexible character, and making it difficult to learn the essential mathematical concepts and the development of the numerical sense. These would be much more enhanced by other more open and less mechanical teaching methods (Martínez, 2008).

\section{The Open Algorithm Based on Numbers (ABN) Method}

For Cerda et al. (2018), there is not much background in the application of the new algorithm models proposed in Mathematics Education, for this reason, the authors propose that students be guided by the ABN method to improve their learning and enhance their performance - intellectual capacity compared to students who are teaching by the traditional method. The ABN method offers better mental ability in problem solving (Adamuz \& Bracho, 2014; Chu et al., 2015).

The ABN methodology represents a significant change in the quantity and quality of achievement in mathematics education. According to Aragon et al. (2017a) and Baroody (2017) students can learn faster and in greater depth, the teaching of $\mathrm{ABN}$ is based on understanding rather than memorization of concepts. In addition, this new method dramatically improves students' ability to estimate mental capacity in calculation and problem solving. Finally, the ABN procedure allows them to perform mathematical calculations according to their ability. This new approach develops an effective improvement in students' motivation and positive attitude towards mathematics (Pérez et al., 2018).

The ABN proposes that students build their own knowledge, another defining characteristic of this model is that, unlike what has been done traditionally, mistakes should not be avoided, but rather removed, diagnosed and acted upon. In fact, they are considered a fabulous learning opportunity that students should take advantage of in order to successfully advance in their learning process (Díaz et al., 2017). For example, when operating the sum of $231+145+3$, through the ABN method the steps shown in Table 1 are followed.

First, write in the first row $1(\mathrm{r} 1)$, the sum $231+145+3$. By placing the quantities horizontally, you have the opportunity to add the units. For example, the number 3 can be added with 231 or 145 , thus constituting only two quantities $234+145$ in row 2 (r2). Row 3 (r3) consists of 3 columns. The first column represents the quantity of the first summand, it was chosen to add to the second summand. The second column is what is left of the first summand. The third column is the sum of the first sum with the second sum. Both the order of the columns and the amounts selected for addition are the person's choice, and they can increase or decrease. Depending on the domain of the calculation that you have, that is to say, that you can choose the sums that you find easier. Then do the whole process in as many steps as you need.

For students it is easier to add high numbers with exact figures, for example, adding 100+200, is easier than adding 145+155. For this reason, the number 234 is broken down into 200 and 34 . Then add 200 to the 
number 145 in row 3 (r3). In row 4 (r4) you proceed in the same way, breaking down 34 as $30+4$, then adding it to the previous number 345, to get 375. Finally add in row 5 (r5) $375+4$ and get the final result 379.

Another defining feature of the $\mathrm{ABN}$ method is that it always provides direct experience with the manipulation of numbers. Emphasizing Ausubel (1976) meaningful learning, with the ABN method students can build their mathematical knowledge on what they already know and have an explanation, that is, about what already makes sense to them. The authors who defend this method confirm that primary school students cannot construct mathematical concepts on signs that do not refer to real facts, events, and actions of everyday life from their experiences, because only in this way can they obtain for understanding. But, students at the high school level, subjects build their own models of thinking (after manipulating simpler ones), allow them to extend their learning to other areas of knowledge and as a result, strengthen their logical reasoning and use less memory (Cerda et al., 2018; Tang \& Li, 2018).

Once the theoretical differences between the ABN and CNB methods have been analyzed, it can be seen that the problem lies in the traditional method used in Ecuadorian mathematical education (CNB). The CNB method limits students to memorizing instructions and working with numbers. Consequently, they are not taught to analyze. It does not allow them to deduce, reflect, or generate concepts, nor does it facilitate mental computation. Therefore, a new method of teaching mathematics should be promoted. The way in which algorithms are taught must be changed. To promote a method that facilitates the understanding of mathematical operations.

\section{Research Objectives}

After describing the current problem, the general objective is set out:

- To promote the open algorithm based on numbers (ABN), as a method of educational innovation for teaching and learning mathematics in Ecuador.

To develop the general objective, the specific objectives of the research are described:

- To teach students mathematical skills using the ABN and CNB method.

- To design an exploratory comparative evaluation.

- To analyze the methods applied by the students in the resolution of the problems.

- Describe the significant differences between ABN geometric reasoning and NBC geometric reasoning.

\section{METHOD}

Quantitative research was used as the research method. The design was experimental - comparative. Experimental designs are produced by manipulation of a given exposure, the researcher tries to study some known factor and its effects in time (Veiga et al., 2008). The comparative design describes similarities and dissimilarities, works with the present being its horizontal display, compares objects that belong to the same genus, is based on the criterion of homogeneity and therefore differs from the simple comparison (Cadena et al., 2017).

Because it is a comparative design, two variables were generated. One variable is the group of students trained with $\mathrm{ABN}$ geometric reasoning, another variable is the group of students trained with CNB geometric reasoning. The relationships between the variables were determined in an experimental way, that is, the procedures and results of the students were analyzed in a comparative way, method recommended by Robinson \& Jin, 2019).

\section{Population and Research Sample}

The population was composed of 320 students from the first cycle of the National University of Education (UNAE) in the province of Cañar, Republic of Ecuador, during the 2019-2020 academic year. As this was a comparative design between two groups, a homogeneous distribution in the number of students was required. A non-probabilistic sample selection of the equitable type was applied (Amable, 2015). Mathematics was applied in 4 careers at the UNAE. Education in Experimental Sciences (EES), Basic Education (BE), Initial Education (EI) and Intercultural Bilingual Education (EBI). The population of 320 students was divided into two groups. Thus, the sample was 160 students of ABN geometric reasoning, and 160 students of $\mathrm{CNB}$ geometric reasoning. Each group was composed of 40 EES students, 40 BE students, 40 EI students, and 40 EBI students (see Table 2). 
Table 2. Study sample distribution

Students from the first cycle of the National University of Education UNAE, 2019-2020.

\begin{tabular}{ccc}
\hline & Methodological training group \\
\hline & ABN & CNB \\
\hline University career & 40 & 40 \\
\hline EES & 40 & 40 \\
\hline BE & 40 & 40 \\
\hline IE & 40 & 40 \\
\hline IBE & 160 & 160 \\
\hline Sub-total & & 320 \\
\hline Total
\end{tabular}

Table 3. Questionnaire applied to ABN and CNB groups Universidad Nacional de Educación UNAE Education EES, BE, IE y IBE

Questionnaire of research
In the following image, a larger equilateral box with ABDC vertices is presented. The line $\mathrm{n}$ is drawn from vertex $\mathrm{C}$ to point $\mathrm{G}$ (midpoint of the $\mathrm{AB}$ side of the square). Similarly, the line $\mathrm{p}$ starting from vertex $\mathrm{B}$ to point $\mathrm{H}$ (midpoint of the $\mathrm{CD}$ side of the square). In a perpendicular way, the line $\mathrm{j}$ is drawn from vertex $\mathrm{A}$ to point $\mathrm{E}$ (midpoint of side $\mathrm{BD}$ of the square), finally the line $\mathrm{k}$ starting from vertex $\mathrm{D}$ to point $\mathrm{F}$ (midpoint of side $\mathrm{AC}$ of the square). On the inside of the square 'ABCD', the intersections of lines $\mathrm{n}$ and $\mathrm{k}$, form point $\mathrm{I}$, the intersections of lines $\mathrm{n}$ and $\mathrm{j}$ form point $\mathrm{L}$, the intersections of line $\mathrm{j}$ and line $\mathrm{p}$ form point $\mathrm{K}$, the intersection of line $\mathrm{k}$ and line $\mathrm{p}$ form point $\mathrm{J}$. The points ILKJ establish the vertices of the minor square (shaded area). If the side $\mathrm{AB}$ has a length of $4 \mathrm{~cm}$. You are asked to calculate the following areas and perimeters.

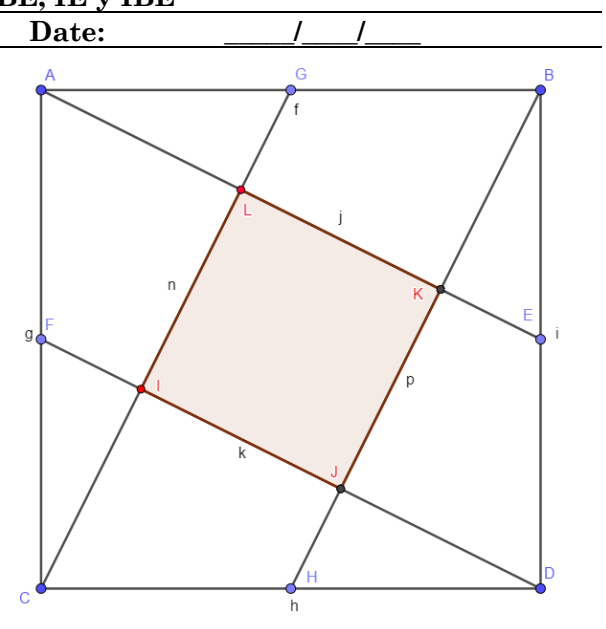

\begin{tabular}{|c|c|c|c|c|c|c|}
\hline \multirow{2}{*}{ Items } & \multirow{2}{*}{ CNB geometric reasoning } & \multicolumn{5}{|c|}{ Options } \\
\hline & & 5 & 4 & 3 & 2 & 1 \\
\hline 1 & The area of this ABDC square is & $16 \mathrm{~cm}^{2}$ & $4 \mathrm{~cm}^{2}$ & $8 \mathrm{~cm}^{2}$ & $2 \mathrm{~cm}^{2}$ & $64 \mathrm{~cm}^{2}$ \\
\hline 2 & The perimeter of the ABDC square is & $16 \mathrm{~cm}^{2}$ & $8 \mathrm{~cm}^{2}$ & $2 \mathrm{~cm}^{2}$ & $4 \mathrm{~cm}^{2}$ & $12 \mathrm{~cm}^{2}$ \\
\hline 3 & The area of this ILKJ square & $3.2 \mathrm{~cm}^{2}$ & $3.4 \mathrm{~cm}^{2}$ & $3 \mathrm{~cm}^{2}$ & $2.8 \mathrm{~cm}^{2}$ & $2 \mathrm{~cm}^{2}$ \\
\hline 4 & The perimeter of the CDF triangle is & $6+\sqrt{20}$ & $4+\sqrt{20}$ & $4+\sqrt{10}$ & $6+\sqrt{5}$ & $3+\sqrt{ } 20$ \\
\hline 5 & The area of the BHD triangle is & 4 & 6 & 8 & 10 & 12 \\
\hline 6 & The area of the CHGB parallelogram & 8 & 9 & 10 & 11 & 16 \\
\hline \multirow[t]{2}{*}{ Items } & ABN geometry reasoning & \multicolumn{5}{|c|}{ Options } \\
\hline & & $\mathbf{N}$ & AN & ST & AA & A \\
\hline 1 & $\begin{array}{l}\text { Were arithmetic operations applied to the calculation of the } \\
\text { perimeter? }\end{array}$ & & & & & \\
\hline 2 & Was Thales' theorem applied to the area calculation? & & & & & \\
\hline 3 & Was Pythagoras' theorem applied to the calculation of perimeter? & & & & & \\
\hline 4 & $\begin{array}{l}\text { For the calculation of perimeter, was it necessary to apply Euclid's } \\
\text { theorem? }\end{array}$ & & & & & \\
\hline 5 & The geometric formula of the area of the triangle was applied & & & & & \\
\hline 6 & The geometric formulation of the area of the square was applied & & & & & \\
\hline
\end{tabular}

\section{Instruments}

This test evaluated mathematical competence and focuses on the analysis of reasoning applied by the ABN group and the CNB, both in terms of skills and concepts. The sub-test of CNB reasoning evaluated concrete results related to accuracy of results, knowledge of numerical facts, CNB calculation and ABN mathematical concepts of basic geometry such as area and perimeter calculation. The instrument applied was a multiple choice questionnaire (five options and six items). The subtest of ABN reasoning is composed of a Likert scale questionnaire (five answer options) where the need or application of theorems, concepts or procedures applied in the resolution of the evaluation exercises is deciphered.

The administration of the evaluation was constituted by a developable questionnaire type model (see Table 3 ). The time required for its performance was about 45 minutes. With the support of the current version of GeoGebra software, the geometric figure of the evaluation was designed. The test is applicable to high school 
Table 4. Correlation matrix of student results in the ABN geometric reasoning and CNB geometric reasoning subtests

\begin{tabular}{|c|c|c|c|c|}
\hline Variable & $\begin{array}{c}\mathrm{ABN} \text { geometry } \\
\text { reasoning }\end{array}$ & $\begin{array}{c}\text { CNB geometric } \\
\text { reasoning }\end{array}$ & ABN calculations & CNB calculations \\
\hline CNB geometric reasoning & 1 & 0.854 & 0.638 & 0.537 \\
\hline CNB calculations & & 1 & 0.201 & 0.849 \\
\hline ABN geometry reasoning & & & 1 & 0.192 \\
\hline ABN calculations & & & & 1 \\
\hline
\end{tabular}

students or students who have just graduated from high school. The answer options were scalar type with five options, for the CNB geometry reasoning test, the correct answers have a value of 5 points maximum. The closest option is 4 , which is an approximate result. Then the value 3 represents an average term. The number 2 is a low value, and the lowest option has a value of 1-point minimum. For the CNB geometric reasoning subtest, the answer choices were of the Likert type with the Never $(\mathrm{N})$ option with the highest scalar value of 5. The Almost Never (AN) option with a value of 4. The Sometimes (ST) option with an intermediate value of 3. The Almost Always (AA) option with a score of 2, and the Always (A) option with the lowest score of 1.

\section{Statistical Analysis}

For the statistical calculation of the comparative analyses between the average scores obtained by the ABN and CNB groups, the Analysis of Variance (ANOVA) technique was applied, which constitutes one of the most valuable tools of Statistical Inference. The one-factor ANOVA is used to compare several groups in a quantitative variable. As an independent group, the statistical results of the "ABN geometric reasoning" variances were considered, and as a dependent group, the "CNB geometric reasoning" variances, for a comparative total of two group means.

This test is a generalization of the contrast of equality of means for two samples. It is applied to contrast the equality of means of three or more independent and normally distributed populations (Mendoza \& Rivero, 2019; Steven, 2009). The ANOVA analysis allows detecting differences in group means, when there is one parametric dependent variable and one or more independent variables. The effect size was also calculated for the total measured variables. Since the homocedasticity of the variations did not develop, a correction of the degrees of freedom was applied with Welch's robust test (Fernandez et al., 2007; Hook, 2017).

\section{RESULTS}

In order to establish equality or equity in the distribution of $\mathrm{ABN}$ and $\mathrm{CNB}$ groups, the test was applied at the same time, with equal orientation and in two separate groups, 160 students with ABN training and 160 students with CNB training. After analyzing the results and deciphering the need to use theorems, the results in Table 4 are presented.

To examine whether there were differences in the outcomes of students in the ANB and CNB groups, significant differences can be observed. In the CNB geometric reasoning subtest, 6 items were presented. Students who answered 3 or more items correctly were considered to have passed. The students oriented with the ABN method, had results of effectiveness with a coefficient of $0.192 p<0.01$. Students oriented with the NBC method had a coefficient of $0.537 \mathrm{p}<0.01$.

Of the 320 students who participated in the test, only the results that were approved are considered. In the CNB geometry reasoning subtest, students who got 3 or more choices right were passed. The total number of passes (N) was 243 students. Students who were trained in ABN methodology. They had a total of 151 passes. Compared to the CNB group with a total of 92 passes. The matrix in Table 5 shows the correlations of the results, the total scores of the $\mathrm{ABN}$ geometric reasoning and CNB geometric reasoning subtests. The results achieved by the students can be analysed to demonstrate the strength of the relationship between them. It is observed that all of them are statistically significant. Statistically significant differences were found ( $\mathrm{p}<0.05$ ), differences between $\mathrm{CNB}$ and $\mathrm{ABN}$ groups in calculation. In the dimension of $\mathrm{ABN}$ reasoning calculations, students from the ABN group, demonstrated not to use theorems or concepts of mathematical formulation. Their most applied answer choice was never or almost never. This group demonstrated not to use formulas and arithmetic operations in the calculation of area and perimeter. On the contrary, of the students of the CNB group, they always and almost always responded. This group emphasized using theorems, formulas. Mathematical procedures to give solutions to the problems posed. The same can be demonstrated in the results of the $\mathrm{CNB}$ geometric reasoning test. 
Table 5. Descriptive statistics of the NBC geometric reasoning test and the ABN geometric reasoning test

\begin{tabular}{|c|c|c|c|c|c|c|c|c|c|}
\hline Variable & Group & $\mathbf{N}$ & M & SD & CI 95\% & Min & $\operatorname{Max}$ & $\mathbf{F}$ & $\mathbf{n}^{2}$ \\
\hline \multirow{3}{*}{$\begin{array}{l}\mathrm{ABN} \text { geometry } \\
\text { reasoning }\end{array}$} & CNB & 160 & 50.03 & 6.87 & $36.06-44.05$ & 1 & 2 & \multirow{3}{*}{$* 3.428$} & \multirow{3}{*}{0.230} \\
\hline & $\mathrm{ABN}$ & 160 & 51.00 & 6.98 & $37.96-45.95$ & 4 & 5 & & \\
\hline & Total & 320 & 51.03 & 6.65 & $36.57-44.50$ & 1 & 5 & & \\
\hline \multirow{3}{*}{$\begin{array}{l}\text { CNB geometric } \\
\text { reasoning }\end{array}$} & CNB & 92 & 47.98 & 6.98 & $43.98-51.98$ & 1 & 3 & \multirow{3}{*}{$* 4.88$} & \multirow{3}{*}{0.243} \\
\hline & $\mathrm{ABN}$ & 151 & 94.05 & 9.89 & $86.05-102.05$ & 4 & 5 & & \\
\hline & Total & 243 & 61.02 & 8.43 & $56.52-65.52$ & 1 & 5 & & \\
\hline \multirow{3}{*}{$\begin{array}{l}\text { CNB Reasoning } \\
\text { Results }\end{array}$} & $\mathrm{CNB}$ & 92 & 0.02 & 0.46 & $-0.05-0.22$ & 1 & 1 & \multirow{3}{*}{$\begin{array}{c}* * 4.93 \\
F(\text { Welch) }\end{array}$} & \multirow{3}{*}{0.049} \\
\hline & $\mathrm{ABN}$ & 151 & 0.08 & 0.86 & $0.21-0.63$ & 4 & 5 & & \\
\hline & Total & 243 & 0.29 & 0.75 & $0.15-0.43$ & 1 & 4 & & \\
\hline
\end{tabular}

$* * \mathrm{p}<0.05 . * \mathrm{p}<0.01$

The ABN group, mostly had more students passed. The CNB group only had a total of 92 passing students. In the CNB reasoning results Welch's $F$ test gave a value of 4.93 and $n 2=0.049$. Statistically significant differences were found in these variables compared $(\mathrm{p}<0.01)$. In particular, the CNB reasoning dimension, a large size difference was found. In addition, significant differences and a large effect size were found.

\section{DISCUSSION}

The purpose of the methodology of teaching mathematics is to achieve a perfection of the aptitude in this science. Another purpose is the optimal development of mathematical thinking. There is little research to support the differences between the ABN method and CNB teaching (Aragón et al., 2017b). This is the main objective of the present study. The results derived from this research demonstrated the following, students instructed with $\mathrm{ABN}$ method obtained better results in the subtest of CNB geometry reasoning.

When analyzing the students' assessments. It was possible to perceive that the CNB group developed mechanical-type strategies. In other words, the entire CNB group applied systematic and standardized procedures, performing a step-by-step analysis, then locating the formula, executing the theorem and calculating the solution. Therefore, the results found are due to traditional teaching methods. General knowledge skills were also distinguished from numbers and estimation skills (Noreen \& Khan, 2019; Pari, 2017). However, the students in the CNB group, excelled in resolutions with a structured and organized design. The structure or traditional method of problem solving is presented by Pérez et al. (2018); Singh (2004) and Usiskin (1995). The author mentions that students perform step-by-step problem solving. The results found are due to the fact that traditional teaching methods are based on automated learning. Scott \& Mjolsness (2019) express that the exercises solved by students trained with traditional methods are structured. The authors also point out that traditional algorithms do not emphasize understanding, only results. As in the study results, it was analyzed that the students were interested in the order and procedure. It was demonstrated that there was no logical understanding of the results.

The results of the evaluation of the group instructed by ABN, did not apply rules. For the analysis of the area calculation, they only developed a scheme or practical drawings. The practical drawings or designs, correspond to a meaningful learning. Kenley (2007) states that a student with a significant and open-minded background in mathematics can break down an exercise. For example, in the ABN group results students solved item 6 in different ways. Some of them broke down the parallelogram into two triangles. Other students generated a square by moving one of the triangles horizontally. In this way, by not recognizing the theorems, as a unique method, the student has the opportunity to generate their own theories or methods of problem solving (Harpreet, 2020; Van den Heuvel \& Drijvers, 2014).

The results were relevant because of the skills used for ABN geometric reasoning. The ability to solve the exercises contributes to the development of mathematical thinking. This is one of the main underpinnings of arithmetic performance. The ABN group demonstrated that it is necessary to establish the basis of interconnected knowledge. A knowledge elaborated from the basic mathematical concepts. For this group, it was not necessary the simple memorization of information and algorithmic procedures (Fernández et al., 2007; García et al., 2009; Martínez, 2008).

Similarly, the ability to apply mathematical procedures was very distinguished and different between the two groups. For the calculation of areas of the "LKJI" square, ABN students did not apply formulas. The ABN group only disfigured the "ABCD" square into 5 parts or five exact or regular squares. Determining that the area of the "LKJI" square is only one-fifth (1/5) of the larger "ABCD" square only arithmetic operations and rational numbers were applied (view Figure 2). 


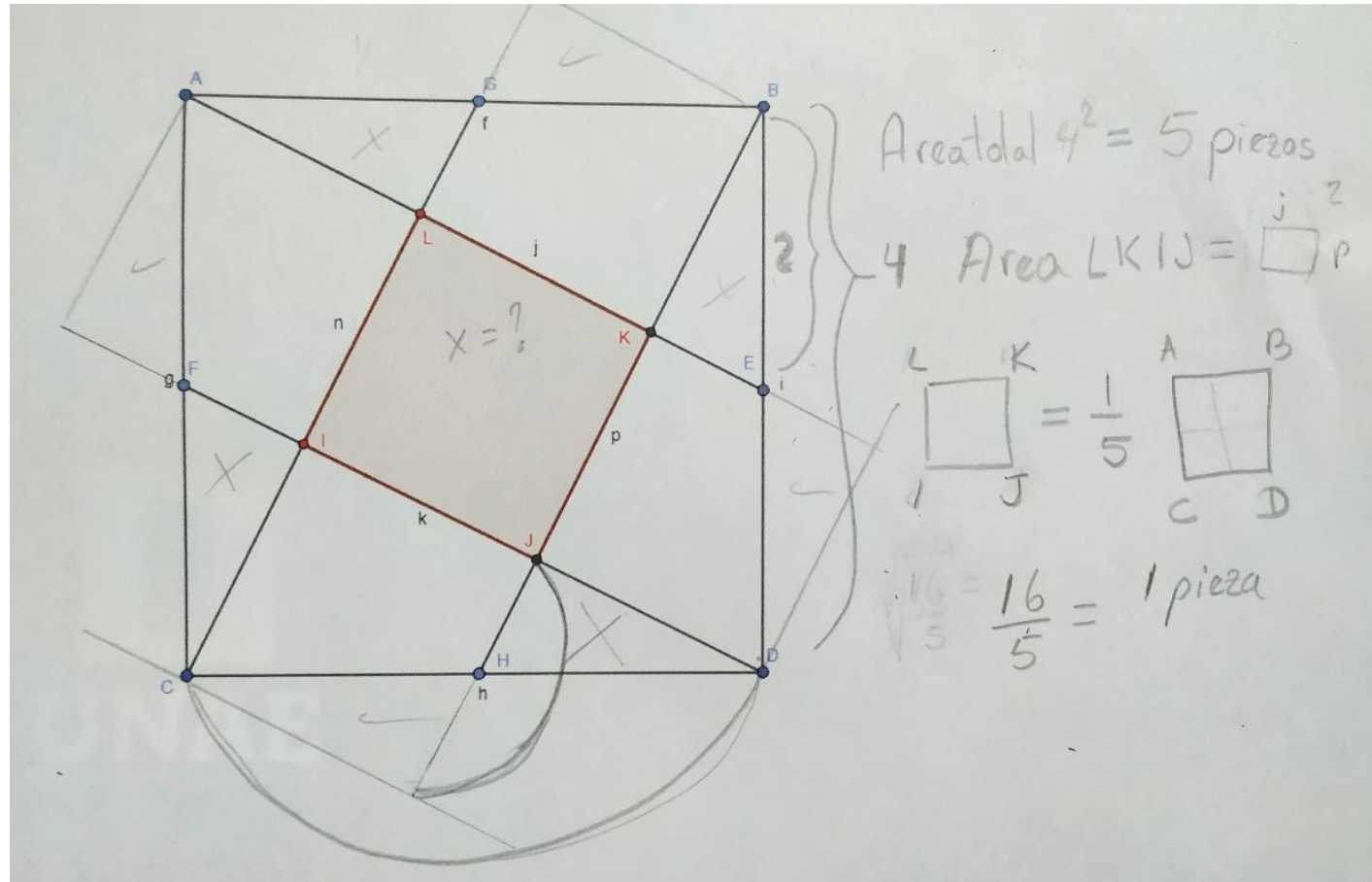

Figure 2. Calculation of the IJKL area, applied by a student trained with the ABN method

Unlike the CNB group, the operations applied were dominated by the use of algebra. Most of them applied the Pythagorean Theorem, to obtain the hypotenuse in the right triangle "ABE". Then, they mostly applied Euclid's theorem to obtain the distance between PK points. Then the theorem of Thales was applied, to obtain in a proportionate way the distance "GL" and "LK". The above data preserve the objective of distinguishing the difference in test results. The effective applicability impact of the ABN method can be seen (Chu et al., 2015; Díaz et al., 2017). An impact on the variables that make up the ABN and CNB geometric reasoning is demonstrated. That is, participants who were in the ABN group scored significantly higher than the CNB group.

\section{CONCLUSION}

With respect to the initially proposed research objective. The results obtained show that training with the ABN method has a favourable impact. In a positive way, compared to the group of students participating in CNB. In the ABN group, it managed to generate changes on the set of their beliefs regarding the nature of mathematics. Changes in the teacher's role and learning expectations. They had a less rigid orientation in these areas. It can be observed from the students; they have a favourable appreciation. Favourable in the relevance and effectiveness of their didactic transposition process. According to the results, it was demonstrated that students learn to solve the exercises, after establishing open standards in geometry and not in algebraic formulation.

Students, when oriented with the ABN method, have better results. The results are positive when the student is allowed to break down the exercise. The use of concrete material establishes a sequence of learning achievements. Learning based on strengthening mathematical skills. Even so, after analyzing in a descriptive way the results issued by the $\mathrm{ABN}$ and CNB groups It can be inferred that the differences found are due to the instructional approach. It should also be mentioned that the effect of the instruction The teacher's open teaching generates significant changes in student learning. Students, when given the opportunity to generate new approaches to resolution, can complement and expand their intellectual capabilities in problem solving.

\section{RECOMMENDATIONS}

Therefore, it is recommended to apply the ABN methodology not only to Ecuadorian university students. It is recommended to use the ABN method from the basic education. In this way, students can be better trained before university. Students can develop more sustainable logical-mathematical thinking. Also, they will have 
significant advances in higher education. The ABN method establishes a favorable impact on mathematical reasoning. It also provides a more solid foundation for performance in the development of geometry, arithmetic, and algebra. Finally, it is considered that the effect of the ABN method could be compared with other types of teaching. It can be described as a flexible or innovative model in the field of mathematics teaching.

\section{Disclosure statement}

No potential conflict of interest was reported by the authors.

\section{Notes on contributors}

Derling Jose Mendoza Velazco - Universidad Nacional de Educación, Ecuador.

Magda Francisca Cejas Martinez - Universidad de las Fuerzas Armadas, ESPE, Ecuador and Universidad Nacional de Chimborazo, UNACH, Ecuador.

Carlos Alban Yanez - Universidad de las Fuerzas Armadas, ESPE, Ecuador.

Yanet Marisol Ortega - Universidad de las Fuerzas Armadas, ESPE, Ecuador.

\section{REFERENCES}

Adamuz, N., \& Bracho, R. (2014). Flexible algorithms for basic operations as a way to encourage social inclusion. Revista Internacional de Educación para la Justicia Social (RIEJS), 3, 37-53.

Alquinga, M. (2018). The teaching and learning of mathematics to through the taptana. Anales de la Universidad Central del Ecuador, 1(376), 113-128. https://doi.org/10.29166/anales.v1i376.1769

Amable, M. (2015). Proposal for a Quantitative Research Process. Applying the Characteristics of the Software Producing Mypes (Micro and Small Enterprises). Interfaces: revista digital de la Carrera de Ingeniería de Sistemas, 8, 71-92.

Amanat, A., \& Reid, N. (2012). Understanding Mathematics: Some Key Factors. European journal of educational research, 1(3), 283-299. https://doi.org/10.12973/eu-jer.1.3.283

Aragón, E., Delgado, C., \& Marchena, E. (2017b). Differences in mathematical learning between ABN and CBC teaching methods. Psychology, Society, \& Education, 9(1), 61-70. https://doi.org/10.25115/psye.v9i1.462

Aragón, E., Mendizábal, M., Marchena, E., Navarro, N., \& Aguilar, M. (2017a). Cognitive profile in learning mathematics with open calculation based on numbers algorithm. Revista de Psicodidáctica, 22(1), 5459. https://doi.org/10.1387/RevPsicodidact.16396

Ausubel, D. (1976). Educational psychology. A cognitive clue point. México: Editorial Trillas.

Barahona, F., Barrera, O., Vaca, B., \& Hidalgo, B. (2015). GeoGebra for Teaching Mathematics and its Impact on Student Achievement. Revista Tecnológica ESPOL - RTE, 28(5), 121-132.

Baroody, A. (2017). The use of concrete experiences in Early Childhood Mathematics Instruction. In Advances in Child Development and Behavior. London: Academic Press. https://doi.org/10.1016/bs.acdb.2017.03.001

Bracho, R., \& Adamuz, N. (2014). Flexible algorithms for basic operations as a way to encourage social inclusion. Revista Internacional de Educación para la Justicia Social, 3(1), 37-53.

Brasch, T. L., Williams, R. L., \& McLaughlin, T. F. (2008). The effects of a direct instruction flashcard system on multiplication fact mastery by two high school students with ADHD and ODD. Child y Family Behavior Therapy, 30(1), 51-59. https://doi.org/10.1300/J019v30n01_04

Cadena-Iñiguez, P., Rendón-Medel, R., Aguilar-Ávila, J., Salinas-Cruz, E., de la Cruz-Morales, F., \& Sangerman-Jarquín, D. (2017). Quantitative methods, qualitative methods or combination of research: an approach in the social sciences. Revista Mexicana de Ciencias Agrícolas, 8(7), 1603-1617. https://doi.org/10.29312/remexca.v8i7.515

Cerda, G., Aragón, E., Pérez, C., Navarro, I., \& Aguilar, M. (2018). The Open Algorithm Based on Numbers $(\mathrm{ABN})$ Method: An Effective Instructional Approach to Domain-Specific Precursors of Arithmetic Development. Frontiers in psychology, 9, 1811. https://doi.org/10.3389/fpsyg.2018.01811 
Chu F. W., van Marle K., \& Geary, D. (2015). Early numerical foundations of young children's mathematical development. J. Exp. Child Psychol, 132, 205-212. https://doi.org/10.1016/j.jecp.2015.01.006

Díaz, M., Torres, N. \& Lozano, M. (2017). New approach to teaching mathematics, the ABN method. International Journal of Developmental and Educational Psychology, 3(1), 431-434. https://doi.org/10.17060/ijodaep.2017.n1.v3.1012

Fernández, P., Livacic, P., \& Vallejo G. (2007). How to choose the best statistical test for analyse a repeated measurement design. International Journal of Clinical and Health Psychology, 7(1), 153-175.

García, B. Coronado, A., \& Montealegre, L. (2011). Formation and development of mathematical competences: a theoretical perspective in the didactics of mathematics. Revista Educación y Pedagogía, 23(59), 159175.

Harpreet, K. (2020). Introducing the concept of angle to young children in a dynamic geometry environment. International Journal of Mathematical Education in Science and Technology, 51(2), 161-182. https://doi.org/10.1080/0020739X.2020.1717657

Hook, J. (2017). Max-Plus Algebraic Statistical Leverage Scores. SIAM Journal on Matrix Analysis and Applications, 38(4), 1410-1433. https://doi.org/10.1137/16M1097596

Kenley, R. (2007). Activity-based teaching for Unitec New Zealand construction students. Emirates Journal for Engineering Research, 12(1), 57-63.

Martínez, J. (2008). Basic math skills. A new practice. Spain: Wolters Kluwer.

Martínez, J. (2011). The method of open calculation based on numbers (ABN) as a future alternative with respect to the closed traditional methods based on figures (CBC). Bordón Revista de Pedagogía, 63(4), 95-110.

Mendoza Velazco, D. J., \& Rivero Padrón, Y. (2019). Teaching Resource for the Teaching of Geometry: Circular Trigonometric Geoplane. International Electronic Journal of Mathematics Education, 14(1), 3-13. https://doi.org/10.12973/iejme/3936

Mendoza, D. J., \& Mendoza, D. I. (2018). Information and Communication Technologies as a Didactic Tool for the Construction of Meaningful Learning in the Area of Mathematics. International Electronic Journal of Mathematics Education, 13(3), 261-271. https://doi.org/10.12973/iejme/3907

Ministry of Education of Ecuador. (2016). Didactic guide of Curricular Implementation for GBS and BGU. Matemática. Mathematics. Quito: National Assembly. Retrieved from http://www.ecuaeduc.com/curri/0/g2.pdf

Navarro, M. J., \& Navarro, J. I. (2015). Differences in mathematical learning between ABN and CBC teaching methods. Revista de Psicología y Educación, 10(2),113-126.

Noreen, R., \& Khan Rana, A. (2019). Activity-Based Teaching versus Traditional Method of Teaching in Mathematics at Elementary Level. Bulletin of Education and Research, 41(2), 145-159.

Pari, A. (2017). The ABN method in the teaching and learning of mathematics. Journal Scientia, 6(1), 100113. https://doi.org/10.1002/t1.20221

Pérez, C., González, I., Cerda, G., \& Benvenuto, G. (2018). The ABN method as an effective articulator of mathematical learning in childhood: experiences in professors of initial cycle in Chile. ECPS Journal, 17, 75-96. https://doi.org/10.7358/ecps-2018-017-pere

Robinson, S., \& Jin, J. (2019). Student academic performance system: quantitative approaches to evaluating and monitoring student progress. International Journal of Quantitative Research in Education, 4(4), 269-353. https://doi.org/10.1504/IJQRE.2019.100170

Rodríguez, C., Celorio, A., \& Gutiérrez, J. (2019). Teaching of basic mathematics in basic general education of Ecuador. Revista científico- educacional de la provincia Granma, 15(2), 217-230.

Scott, C., \& Mjolsness, E. (2019). Multilevel Artificial Neural Network Training for Spatially Correlated Learning. SIAM Journal on Scientific Computing, 41(5), S297-S320. https://doi.org/10.1137/18M1191506

Singh, M. (2004). Modern teaching of Mathematics. New Delhi: Anmol publications PVT. LTD.

Steven, F. (2009). Analysis of Variance: The Fundamental Concepts. Journal of Manual \& Manipulative Therapy, 17(2), 27E-38E. https://doi.org/10.1179/jmt.2009.17.2.27E

Tang, X., \& Li, X. (2018). Biderivations of the twisted Heisenberg-Virasoro algebra and their applications. Communications in Algebra, 46(6), 2346-2355. https://doi.org/10.1080/00927872.2017.1378896

Usiskin, Z. (1995). Transition Mathematics. Florida: Addison Wesley/Scott Foresman. 
Van den Heuvel, M., \& Drijvers, P. (2014). Realistic Mathematics Education. In: S. Lerman (ed.) Encyclopedia of Mathematics Education. Springer Science+Business Media Dordrecht.

Veiga de Cabo, J., Fuente Díez, E., \& Zimmermann Verdejo, M. (2008). Study models in applied research: concepts and criteria for design. Medicina y Seguridad del Trabajo, 54(210), 81-88. https://doi.org/10.4321/S0465-546X2008000100011

Weiland, T., Orrill, Ch., Brown, R., \& Nagar, G. (2019). Mathematics teachers' ability to identify situations appropriate for proportional reasoning. Research in Mathematics Education, 21(3), 233-250. https://doi.org/10.1080/14794802.2019.1579668

Zambak, V., \& Tyminski, A. (2020). Examining mathematical technological knowledge of pre-service middle grades teachers with Geometer's Sketchpad in a geometry course. International Journal of Mathematical Education in Science and Technology, 51(2), 183-207. https://doi.org/10.1080/0020739X.2019.1650302 